\title{
A New Correlation Method for Estimating Thermal Conductivity of Carbon Dioxide in Liquid, Vapor and Supercritical Phases
}

\author{
Hossein Rostamian', Mohammad Nader Lotfollahi* \\ ${ }^{1}$ Faculty of Chemical, Petroleum and Gas Engineering, Semnan University, 35131-19111 Semnan, P. O. B. 35195-363, Iran \\ * Corresponding author, e-mail: mnlotfollahi@semnan.ac.ir
}

Received: 26 June 2018, Accepted: 11 September 2018, Published online: 28 March 2019

\begin{abstract}
In this study, a new correlation for estimating thermal conductivity (TC) of carbon dioxide was developed based on 2319 data points. The data points were at the temperature ranging from 250 to $1100 \mathrm{~K}$, pressure ranging from 1 to 3000 bar and density ranging from 0.3 to $1400 \mathrm{Kg} \cdot \mathrm{m}^{-3}$ in different phases of liquid, vapor and supercritical. The statistical parameters including average absolute deviation $(A A D \%)$, average percent relative error $(A R E \%)$, sum of absolute residual $(S A R)$ and the coefficient of determination $\left(R^{2}\right)$ have been calculated to evaluate the accuracy of present correlation. The obtained values of $A A D \%, A R E \%$, SAR and $R^{2}$ were $1.98,-0.64,3510.1$ and 0.995 , respectively. The predictions of proposed correlation were also compared with three widely used correlations. The results showed that the proposed correlation is able to accurately calculate thermal conductivity of carbon dioxide. In addition, the proposed model is superior to all the existing empirical models considered.
\end{abstract}

Keywords

thermal conductivity, new correlation, carbon dioxide

\section{Introduction}

The accurate knowledge of transport properties plays an important role in process design. Among the transport properties, thermal conductivity (TC) is one of the crucial parameters in process design due to its effects on heat transfer capability and energy efficiency $[1,2]$. Thermal conductivity is also needed to design refrigerator and air conditioning equipment $[3,4]$. Therefore, the accurate description of TC is essential.

Carbon dioxide is a non-toxic, non-flammable, relatively cheap solvent with further advantages like low viscosity, high diffusivity and ease of usage. Liquid carbon dioxide $\left(\mathrm{L}-\mathrm{CO}_{2}\right)$ and supercritical carbon dioxide $\left(\mathrm{SC}-\mathrm{CO}_{2}\right)$ are good candidates as an environmentally friendly extraction solvent for essential oils and other herbal distillates $[5,6]$. Additionally, L-CO $\mathrm{CO}_{2}$ and $\mathrm{SC}-\mathrm{CO}_{2}$ can be applied to $\mathrm{L}-\mathrm{CO}_{2}$ dry cleaning systems [7], liquid carbon dioxide fracturing process [8], enhanced oil recovery (EOR) [9], friction stir welding using liquid $\mathrm{CO}_{2}$ rapid cooling [10], and other applications as a refrigerant fluid [11].

The thermal conductivity of $\mathrm{L}-\mathrm{CO}_{2}$ and $\mathrm{SC}-\mathrm{CO}_{2}$ are applied in most of industries that $\mathrm{CO}_{2}$ is used. However, the experimental TC data for carbon dioxide are limited especially in liquid and supercritical phases due to its expensive and time-consuming experimental measurement. Therefore, it is desirable to construct a simple and accurate method for predicting the $\mathrm{TC}$ of $\mathrm{CO}_{2}$.

The models for TC calculation are generally classified into two different groups including intelligent methods and correlation methods $[12,13]$. The intelligent methods such as artificial neural network models (ANN) are reliable and accurate predictive models, which could be used for interpolation and extrapolation of data. Despite good accuracy of them in most of cases, they are considered as black-box models because there is no visual equation between inputs and outputs of the model [14].

The correlation models are applied in different applications due to their simplicity and fast running time. The advantage of a correlation approach (as a tangible and white-box model) over the intelligent methodology is that they present a mathematical and visual equation [15]. The parameters of these models are obtained by minimizing the deviation between correlation results and experimental data. On the 
other hand, the intelligent method is more accurate than the correlation approach in extrapolation [16].

In recent decades, many modeling investigations have been proposed to calculate $\mathrm{TC}$ of $\mathrm{CO}_{2}$ and other fluids [12, 17, 18]. In 2014, Jarrahian and Heidaryan [19] also developed a new correlation for natural gas thermal conductivity as a function of temperature, pressure and composition. Their model was based on 731 experimental data in temperature range of 220-425 $\mathrm{K}$ and pressure range of 0.1-300 MPa. Eslamloueyan and Khademi [20] used an ANN model based on feed forward three-layer to model the TC of pure gases versus molecular weight, critical temperature and critical pressure at atmospheric pressure. Shams et al. [21] applied 550 data points and presented a calculation approach of least square support vector machine (LSSVM) for describing $\mathrm{TC}$ of $\mathrm{CO}_{2}$. Di Nicola et al. [13] improved their previous correlation for calculating TC [22] versus reduced temperature for the refrigerant family. They considered 41 refrigerant fluids and 1372 experimental data for their correlation at the reduced temperature ranging from 0.30 to 0.95 .

Latini and Sotte [4] compared three different methods for modeling the TC of pure liquid refrigerants including methane, ethane and propane components. The reduced temperatures were in the range of (0.30-0.95). Jarrahian and Heidaryan [3] proposed a new correlation for calculating the TC of $\mathrm{SC}-\mathrm{CO}_{2}$. They used 668 experimental data in the temperature ranging (310 to 960 ) $\mathrm{K}$ and pressure ranging (74 to 2100) bar.

$$
\lambda=\frac{A_{1}+A_{2} P+A_{3} P^{2}+A_{4} \operatorname{Ln}(T)+A_{5} \operatorname{Ln}(T)^{2}}{1+A_{6} P+A_{7} \operatorname{Ln}(T)+A_{8} \operatorname{Ln}(T)^{2}+A_{9} \operatorname{Ln}(T)^{3}}
$$

where $\lambda$ is thermal conductivity in $\mathrm{mW} \cdot \mathrm{m}^{-1} \cdot \mathrm{K}^{-1}$. This correlation is based on a function of pressure and temperature and has nine parameters.

Bahadori and Vuthaluru [23] proposed a new model for $\mathrm{TC}$ of $\mathrm{CO}_{2}$ by utilizing sixteen model parameters. The temperatures and pressures were in the range of (260-450) K and (10-70) MPa, respectively. Bahadori and Vuthaluru [23] suggested Eq. (2):

$$
\ln =a+\frac{b}{p}+\frac{c}{p^{2}}+\frac{d}{p^{3}}
$$

where $a, b, c$ and $d$ are the parameters of model that described by Eqs. (3)-(6):

$$
a=A_{1}+\frac{B_{1}}{T}+\frac{C_{1}}{T^{2}}+\frac{D_{1}}{T^{3}}
$$

$b=A_{2}+\frac{B_{2}}{T}+\frac{C_{2}}{T^{2}}+\frac{D_{2}}{T^{3}}$

$c=A_{3}+\frac{B_{3}}{T}+\frac{C_{3}}{T^{2}}+\frac{D_{3}}{T^{3}}$

$d=A_{4}+\frac{B_{4}}{T}+\frac{C_{4}}{T^{2}}+\frac{D_{4}}{T^{3}}$.

Amooey [24] suggested a new correlation as a function of temperature and density to model the TC of $\mathrm{SC}-\mathrm{CO}_{2}$ by applying 600 experimental points at the temperatures ranging (290-800) $\mathrm{K}$ and densities ranging (1-1200) Kg. $\mathrm{m}^{-3}$ which is by Eq. (7):

$\lambda=\frac{A_{1}+A_{2} \rho+A_{3} \rho^{2}+A_{4} \rho^{3} T^{3}+A_{5} \rho^{4}+A_{6} T+A_{7} T_{2}}{\sqrt{T}}$.

Ahmadi and Baghban [25] expressed thermal conductivity of supercritical carbon dioxide by two model including a mathematical correlation and GA-LSSVM model as a function of pressure, temperature and density in the temperature range of 294-961 K and pressure range of 0.1-127 MPa. These models were developed by using a databank of including 745 data points. They proposed a correlation contains eight tuned parameters by Eq. (8):

$\lambda=a_{1}+a_{2} T+a_{3} P+a_{4} d+a_{5} T^{1.5} P+a_{6} T d+a_{7} P^{0.8} d^{2}+a_{8} P^{3}$

where the unit of temperature $(T)$, pressure $(P)$, density $(d)$ and thermal conductivity $(\lambda)$ are $\mathrm{K}, \mathrm{MPa}, \mathrm{kg} / \mathrm{m}^{3}$ and $\mathrm{mW} \cdot \mathrm{m}^{-1} \cdot \mathrm{K}^{-1}$ respectivly.

They compared their proposed equation with some other correlations such as Amooey [24] equation. The results of their study showed that Amooey [24] correlation is more accurate than their correlation.

Rostami et al. [26] used genetic programming (GP) to extend a comprehensive model for $\mathrm{SC}-\mathrm{CO}_{2}$ thermal conductivity prediction as a function of pressure, temperature and density by Eqs. (9), (10):

$$
\begin{aligned}
\lambda & =A_{1} T+A_{2} P+A_{3} \rho+A_{4} \operatorname{Ln}(\rho)+\frac{A_{5} P}{T}+A_{6} P^{2}+A_{7} \rho^{2} \\
& +\frac{A_{8} \rho}{T P}+A_{9}
\end{aligned}
$$

for $P<20 \mathrm{Mpa}$,

$\lambda=B_{1} T+B_{2} P+B_{3} \rho+B_{4} \operatorname{Ln}(\operatorname{Ln}(\rho))+B_{5} \operatorname{Ln}(P)+B_{6} T^{2}+B_{7}$

for $P \geq 20 \mathrm{MPa}$,

where $\lambda, T, P$ and $\rho$ indicate thermal conductivity in $\mathrm{W} \cdot \mathrm{m}^{-1} \cdot \mathrm{K}^{-1}$, temperature in $\mathrm{K}$, pressure in $\mathrm{MPa}$, and density in $\mathrm{kg} / \mathrm{m}^{3}$, 
respectively. Also $A_{1}-A_{9}$ and $B_{1}-B_{7}$ are tuned coefficients. For more accuracy, they introduced two separate correlations one correlation for pressures less than $20 \mathrm{MPa}$ and other one for pressures more than $20 \mathrm{MPa}$.

Based on the literature reviews, there are several drawbacks in many of the previous models for thermal conductivity of $\mathrm{CO}_{2}$. For example, the application range of them is limit and they are not applicable over wide ranges of temperature and pressure. In addition, most of those models are only used for one phase and they have significant deviation in other phases. Some other models are too complex and require too much input data.

The aim of this work is developing an accurate, simple and fast running time correlation for calculating the $\mathrm{CO}_{2}$ thermal conductivity for liquid, vapor and $\mathrm{SC}-\mathrm{CO}_{2}$ at the temperature ranging (250-1100) $\mathrm{K}$, pressure ranging (1-3000) bar and density ranging (0.3-1400) Kg.m ${ }^{-3}$. The input variables of this model are temperature and density. In comparison to the previous models, the new proposed model is able to calculate thermal conductivity of $\mathrm{CO}_{2}$ in liquid, gas and supercritical phases.

\section{Methodologies}

\subsection{Description of the new proposed correlation and density calculations}

The main aim of present work is to propose an approach to predict the $\mathrm{TC}$ of $\mathrm{CO}_{2}$ with higher accuracy in comparison to the other correlations available in the literature. The proposed correlation can be applicable for liquid, vapor and $\mathrm{SC}-\mathrm{CO}_{2}$ as a function of temperature and density. This correlation with ten model parameters $\left(\beta_{1}-\beta_{10}\right)$ is expressed by Eq. (11):

$$
\lambda=\frac{\beta_{1}+\frac{\beta_{2}}{T}+\frac{\beta_{3}}{T^{2.5}}+\beta_{4} \rho+\beta_{5} \rho^{2.5} T^{2.5}+\beta_{6} \rho^{3}}{1+\frac{\beta_{7}}{T}+\frac{\beta_{8}}{T^{2.5}}+\frac{\beta_{9}}{T^{3}}+\beta_{10} \sqrt{\rho T}} .
$$

In Eq. (11), $T$ and $\rho$ show temperature in $\mathrm{K}$ and density in $\mathrm{Kg} \cdot \mathrm{m}^{-3} \cdot \lambda$ represents TC in $\mathrm{W} \cdot \mathrm{m}^{-1} \cdot \mathrm{K}^{-1}$.

Since the present correlation is a function of density, the accurate estimation of density in three phases of liquid, vapor and $\mathrm{SC}-\mathrm{CO}_{2}$ is very important. Therefore, the corrected Redlich-Kwong equation of state proposed in our previous work [27] has been applied. This model describes the densities of the liquid, vapor and supercritical $\mathrm{C}_{2} \mathrm{H}_{6}$ and $\mathrm{CO}_{2}$ for wide ranges of temperature and pressure. The corrected RK-EoS is by Eq. (12):

$$
P=\frac{R T}{v-b}-\frac{\beta a}{v(v+b)}
$$

where $\beta$ is defined as a function of $T_{r}$ and $P_{r}$ :

$$
\beta=\frac{\alpha_{1}+\alpha_{2} T_{r}+\alpha_{3} P_{r}^{0.45}}{1+\alpha_{4} T_{r}+\alpha_{5} P_{r}+\alpha_{6} P_{r}^{0.45}} .
$$

In Eq. (13), $\alpha_{1}-\alpha_{6}$ are the model parameters reported in our previous work [27].

\subsection{Data acquisition}

One of the steps that must be taken to create a reliable model is to utilize accurate and reliable experimental sources of data with wide ranges. A data bank including extensive number of 2319 data points were gathered from the literatures [28-33].

A brief overview of thermodynamic conditions in which the experimental TC data are available is presented in Table 1 and Fig. 1.

Table 1 The thermal conductivity data

\begin{tabular}{lcccc}
\hline Refrences & $T(\mathrm{~K})$ & $P(\mathrm{MPa})$ & $\rho\left(\mathrm{Kg} / \mathrm{m}^{3}\right)$ & $\mathrm{ND}^{*}$ \\
\hline Scot et al. [28] & $301-349$ & $0.3-25$ & $4.9-860$ & 92 \\
Johns et al. [29] & $380-474$ & $1.8-30$ & $20-552$ & 47 \\
Pátek et al. [30] & $298-427$ & $0.5-15$ & $8.2-321$ & 77 \\
Leneindre et al. [31] & $293-802$ & $0.1-128$ & $0.7-1145$ & 493 \\
Vesovic et al. [32] & $260-1000$ & $0.1-100$ & $0.7-1100$ & 400 \\
NIST data base [33] & $250-1100$ & $0.1-300$ & $0.3-1400$ & 1210 \\
Total & $250-1100$ & $0.1-300$ & $0.3-1400$ & 2319 \\
\hline *Number of data & & & &
\end{tabular}

*Number of data

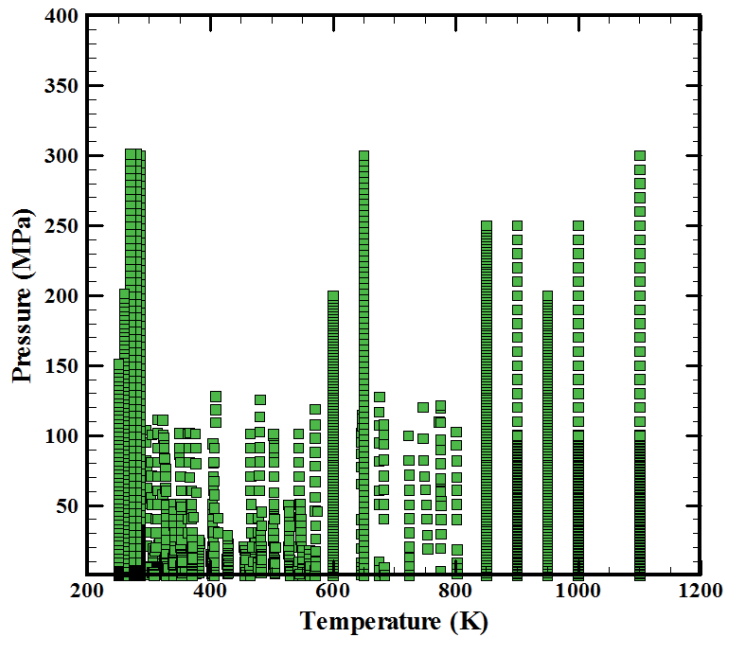

Fig. 1 An overview of the temperatures and pressures in which the experimental TC data are available 


\section{Results and discussion}

In this modeling study, a new correlation has been suggested to reproduce the $\mathrm{TC}$ of $\mathrm{CO}_{2}$ over wide ranges of thermodynamic conditions in different phases of liquid, vapor and supercritical. The experimental data contain 2319 data points in temperature range of (250 to 1100$) \mathrm{K}$, pressure range of (1 to 3000$)$ bar and density range of (0.3 to 1400$) \mathrm{Kg} \cdot \mathrm{m}^{-3}$.

In order to obtain model parameters $\left(\beta_{1}-\beta_{10}\right)$ in Eq. (11), the error minimization between the correlation results and the experimental data was done based on the Nedler-Mead optimization method. The average absolute deviation percentage $(A A D \%)$ expressed by Eq. (14):

$$
A A D \%=\frac{100}{N} \sum_{i} \frac{\left|\lambda_{i, \exp }-\lambda_{i, \text { calc }}\right|}{\lambda_{i, \exp }}
$$

where $N$ represents the number of experimental data. The obtained parameters of the proposed correlation have been listed in Table 2.

To recognize the reliability of proposed correlation for reproducing the thermal conductivities of $\mathrm{CO}_{2}$, the statistical parameters including average percent relative error $(A R E \%)$, sum of absolute residual $(S A R)$ and the coefficient of determination $\left(R^{2}\right)$ have been calculated. $A R E \%$, $S A R$ and $R^{2}$ are by Eqs. (15)-(17):

$$
\begin{aligned}
& A R E \%=\frac{100}{N} \sum_{i}\left(\frac{\lambda_{i, \exp }-\lambda_{i, \text { calc }}}{\lambda_{i, \exp }}\right) \\
& S A R=\sum\left|\lambda_{i, \exp }-\lambda_{i, \text { calc }}\right| \\
& R^{2}=1-\frac{\sum_{i}\left(\lambda_{i, \exp }-\lambda_{i, \text { calc }}\right)^{2}}{\sum_{i}\left(\lambda_{\text {mean }}-\lambda_{i, \exp }\right)}
\end{aligned}
$$

where $\lambda_{\text {mean }}$ is the mean of experimental data for thermal conductivities. When $R^{2}$ is very close to unity, the model acts well.

The overall performance of the proposed correlation in reproducing the TC of vapor, liquid and $\mathrm{SC}-\mathrm{CO}_{2}$ demonstrated in Figs. 2 and 3.

Figs. 4 and 5 show the percentage of absolute relative error $\left(A R_{E} \%\right)$ of the thermal conductivities calculated by Eq. (11) versus density and temperature, respectively. $A R_{E} \%$ is by Eq. (18):

$$
A R_{E} \%=\frac{\left|\lambda_{i, \exp }-\lambda_{i, \text { calc }}\right|}{\lambda_{i, \exp }} \times 100 .
$$

Table 2 The obtained parameters of the proposed correlation.

\begin{tabular}{lc}
\hline Parameters & Tuned parameters \\
\hline$\beta_{1}$ & $-29.9717451505165 \mathrm{e}+015$ \\
$\beta_{2}$ & $9.65637447009372 \mathrm{e}+018$ \\
$\beta_{3}$ & $-13.82889448229492 \mathrm{e}+021$ \\
$\beta_{4}$ & $-21.1152877719961 \mathrm{e}+012$ \\
$\beta_{5}$ & $9.26006733304733 \mathrm{e}+000$ \\
$\beta_{6}$ & $-30.7171646680127 \mathrm{e}+006$ \\
$\beta_{7}$ & $-408.256276723566 \mathrm{e}+015$ \\
$\beta_{8}$ & $130.491020289031 \mathrm{e}+018$ \\
$\beta_{9}$ & $-13.4237924607890 \mathrm{e}+021$ \\
$\beta_{10}$ & $60.9547298940653 \mathrm{e}+009$ \\
\hline
\end{tabular}

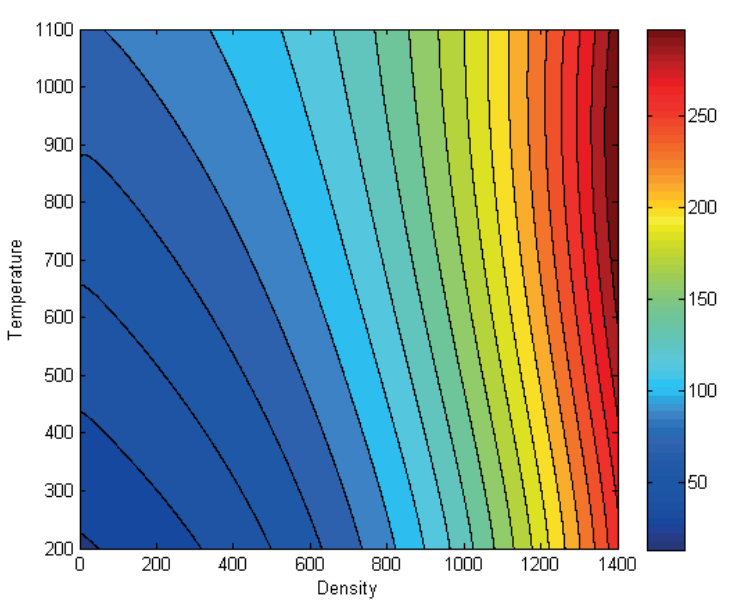

Fig. 2 The overall performance of the proposed correlation in reproducing $\mathrm{TC}$ of vapor, liquid and $\mathrm{SC}-\mathrm{CO}_{2}$ (contour plot).

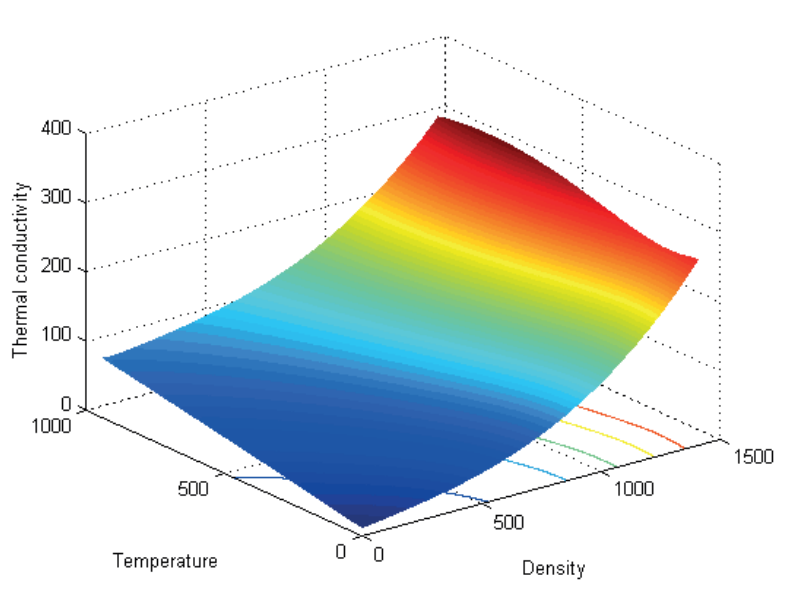

Fig. 3 The overall performance of the proposed correlation in reproducing the $\mathrm{TC}$ of vapor, liquid and $\mathrm{SC}-\mathrm{CO}_{2}$ (3D plot) 


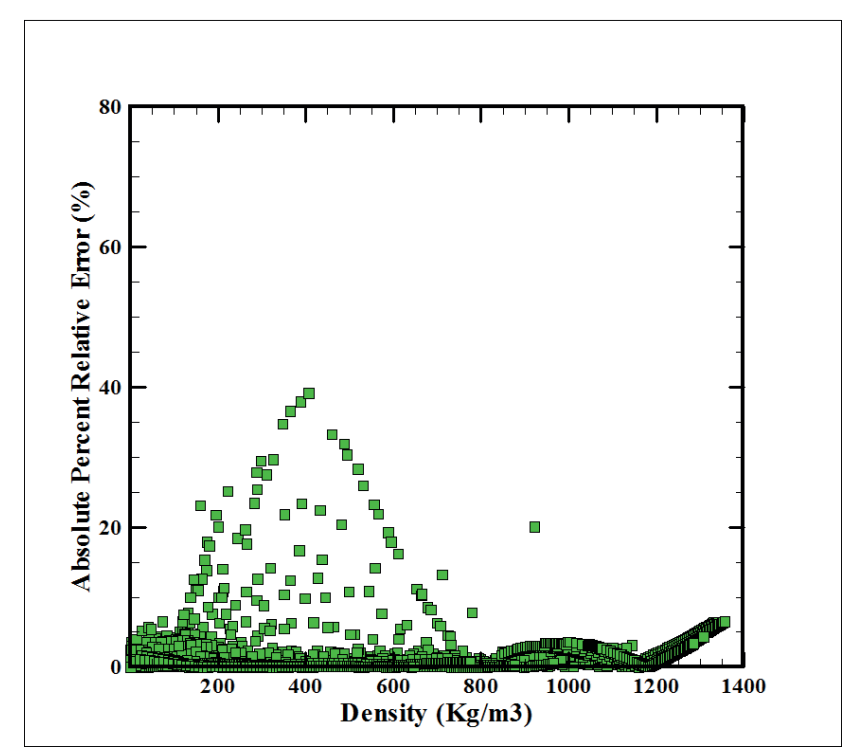

Fig. $4 A R_{E} \%$ of proposed correlation as a function of density

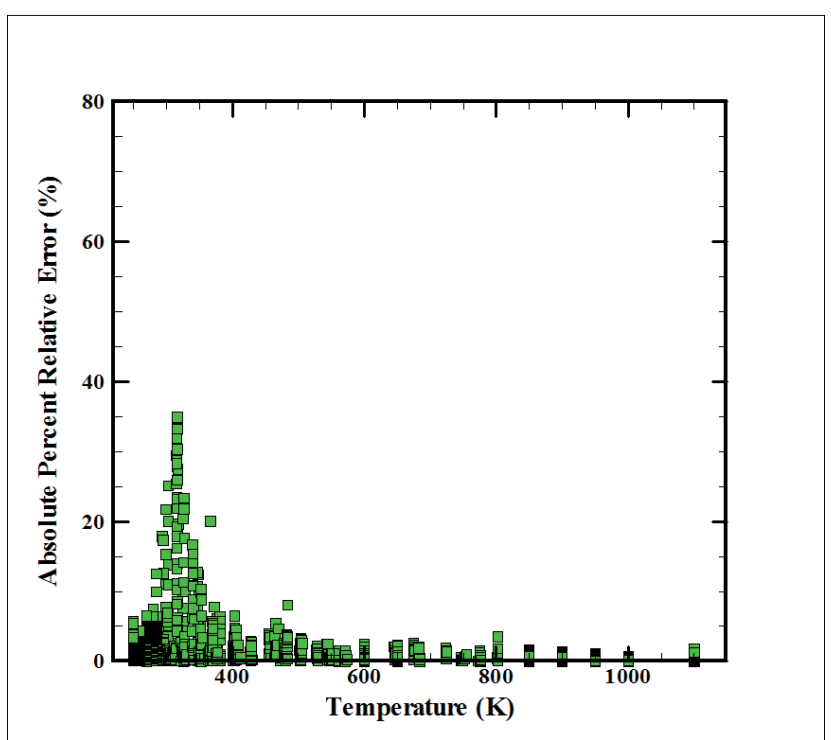

Fig. $5 A R_{E} \%$ of proposed correlation as a function of temperature

Based on Figs. 4 and 5, one can see that $A R E \%$ of main parts of data points are lower than $4 \%$ which is acceptable for engineering purposes. As mention the total number of experimental data is 2319 .

In order to recognize the advantages of the present correlation, the results of it compared with those of four widely used correlations. The selected correlations have been suggested in the literature as the best correlation methods. Table 3 reports the statistical parameters for the proposed model and other correlation methods. As can be seen in Table 3, the proposed model has $R^{2}$ and $A A D \%$ values of 0.995 and $1.98 \%$, where these values for other correlations of Bahadori and Vuthaluru [23], Jarrahian and Heidaryan [3], Amooey [24] and Rostami et al. [26] are
Table 3 The statistical parameters for the proposed model and other correlation methods

\begin{tabular}{lcccc}
\hline Correlation & $A A D \%$ & $S A R$ & $A R E \%$ & $R^{2}$ \\
\hline Proposed model & 1.98 & 3510 & -0.64 & 0.995 \\
Rostami et al. - 2017 [26] & 3.77 & 6843 & 1.82 & 0.968 \\
$\begin{array}{l}\text { Amooey - 2014 [24] } \\
\text { Jarrahian and Heidaryan - }\end{array}$ & 5.35 & 10635 & -3.29 & 0.978 \\
$\begin{array}{l}\text { 2012 [3] } \\
\begin{array}{l}\text { Bahadori and Vuthaluru- } \\
\text { 2010 [23] }\end{array}\end{array}$ & 259.2 & 324016 & 246 & 0.039 \\
\hline
\end{tabular}

0.039 and $259.2 \%, 0.851$ and $22.9 \%, 0.978$ and $5.35 \%$, 0.968 and $3.77 \%$, respectively. This comparison shows that new correlation model is more accurate for reproducing the $\mathrm{TC}$ of $\mathrm{CO}_{2}$ over wide ranges of thermodynamic conditions. The proposed model is able to successfully cover three phases of liquid, vapor, and supercritical $\mathrm{CO}_{2}$, while other models cover only the supercritical $\mathrm{CO}_{2}$ and have poorer performance than the proposed model. Therefore, the main advantage of this work is its capability to be used in liquid, vapor, and supercritical phases with high accuracy.

Fig. 6 shows comparison between the proposed correlation and other four correlations. The tightest cloud of points around the $45^{\circ}$ line is belonged to the proposed model and the most scattering of the points is assigned to Bahadori and Vuthaluru [23] model. As it is shown in this figure, the predicted values of proposed model are in good agreement with the experimental data; however, the considerable scattering of the data points can be seen in the other models, especially in Bahadori and Vuthaluru [23] and Jarrahian and Heidaryan [3] models.

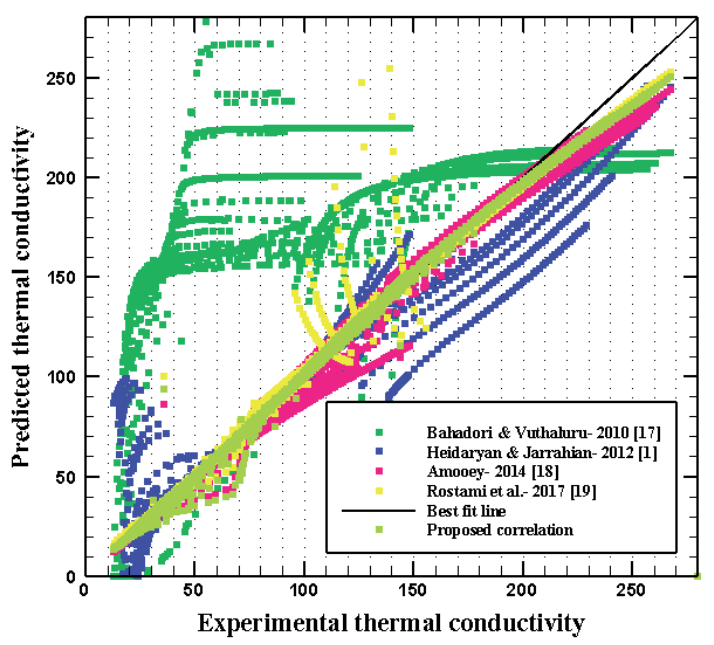

Fig. 6 Proposed correlation outputs compared with other four correlations. 
The reasons of weak performance of both Jarrahian and Heidaryan [3] and Bahadori and Vuthaluru [23] models are related to their limiting temperature and pressure ranges and less numbers of data points for constructing these models. Therefore, these correlations have low accuracy in the estimation of $\mathrm{CO}_{2}$ thermal conductivity for larger databank including wider ranges of temperature and pressure. Hence, the proposed correlation can accurately predict $\mathrm{TC}$ of $\mathrm{CO}_{2}$ in liquid, vapor and supercritical phases.

\section{Conclusion}

In this modeling investigation, a new density based model was proposed and its accuracy was compared with other widely used correlations. The accuracy of new proposed

\section{References}

[1] Rad, F. M., Fung, A. S., Leong, W. H. "Feasibility of combined solar thermal and ground source heat pump systems in cold climate, Canada", Energy and Buildings, 61, pp. 224-232, 2013. https://doi.org/10.1016/j.enbuild.2013.02.036

[2] Salari, E., Peyghambarzadeh, S. M., Sarafraz, M. M., Hormozi, F. "Boiling Thermal Performance of $\mathrm{TiO}_{2}$ Aqueous NanoFluids as a Coolant on a Disc Copper Block", Periodica Polytechnica Chemical Engineering, 60(2), pp. 106-122, 2016. https://doi.org/10.3311/PPch.8262

[3] Jarrahian, A., Heidaryan, A. "A novel correlation approach to estimate thermal conductivity of pure carbon dioxide in the supercritical region", The Journal of Supercritical Fluids, 64, pp. 39-45, 2012. https://doi.org/10.1016/j.supflu.2012.02.008

[4] Latini, G., Sotte, M. "Thermal conductivity of refrigerants in the liquid state: A comparison of estimation methods", International Journal of Refrigeration, 35(5), pp. 1377-1383, 2012.

https://doi.org/10.1016/j.ijrefrig.2012.04.009

[5] Rostamian, H., Lotfollahi, M. N. "A New Simple Equation of State for Calculating Solubility of Solids in Supercritical Carbon Dioxide", Periodica Polytechnica Chemical Engineering, 59(3), pp. 174-185, 2015.

https://doi.org/10.3311/PPch.7714

[6] Baseri, H., Lotfollahi, M. N., Asl, A. H. "Effects of Some Experimental Parameters on Yield and Composition of Supercritical Carbon Dioxide Extracts of Cinnamon Bark", Journal of Food Process Engineering, 34(2), pp. 293-303, 2011.

https://doi.org/10.1111/j.1745-4530.2008.00355.x

[7] van Roosmalen, M. J. E., van Diggelen, M., Woerlee, G. F., Witkamp, G. J. "Dry-cleaning with high-pressure carbon dioxide-the influence of mechanical action on washing-results", The Journal of Supercritical Fluids, 27(1), pp. 97-108, 2003. https://doi.org/10.1016/S0896-8446(02)00212-7

[8] Sun, X., Wang, Z., Sun, B., Wang, W. "Research on hydrate formation rules in the formations for liquid $\mathrm{CO}_{2}$ fracturing", Journal of Natural Gas Science and Engineering, 33, pp. 1390-1401, 2016. https://doi.org/10.1016/j.jngse.2016.06.045 model was investigated by various graphical and statistical methods. Based on 2319 data points from the literature, the mean $A A D \%$ for the proposed model was $1.98 \%$; where, this value for other equations were $3.77 \%, 5.35 \%$, $22.9 \%$ and $259.2 \%$. The results showed that in spite of simplicity, the proposed model has presented accurate results of TC for carbon dioxide. On the other hand, the correlations suggested in the literature have some limitations being their limiting temperature and pressure ranges and as a result their application only for supercritical region. However, the correlation model developed in this work is able to successfully cover three phases of liquid, vapor, and supercritical $\mathrm{CO}_{2}$ with high accuracy in the wide ranges of thermodynamic conditions.

[9] Mazzotti, M., Pini, R., Storti, G. "Enhanced coalbed methane recovery", The Journal of Supercritical Fluids, 47(3), pp. 619-627, 2009. https://doi.org/10.1016/j.supflu.2008.08.013

[10] Charoenchaitrakool, M., Tungkasatan, S., Vatanatham, T., Limtrakul, S. "Cleaning of lubricant-oil-contaminated plastic using liquid carbon dioxide", Journal of Industrial and Engineering Chemistry, 34, pp. 313-320, 2016. https://doi.org/10.1016/j.jiec.2015.12.009

[11] Santosa, I. D. M. C., Gowreesunker, B. L., Tassou, S. A., Tsamos, K. M., Ge, Y. "Investigations into air and refrigerant side heat transfer coefficients of finned-tube $\mathrm{CO}_{2}$ gas coolers", International Journal of Heat and Mass Transfer, 107, pp. 168-180, 2017. https://doi.org/10.1016/j.ijheatmasstransfer.2016.11.011

[12] Tatar, A., Barati-Harooni, A., Najafi-Marghmaleki, A., NorouziFarimani, B., Mohammadi, A. H. "Predictive model based on ANFIS for estimation of thermal conductivity of carbon dioxide", Journal of Molecular Liquids, 224(B), pp. 1266-1274, 2016. https://doi.org/10.1016/j.molliq.2016.10.112

[13] Di Nicola, G., Ciarrocchi, E., Coccia, G., Pierantozzi, M. "Correlations of thermal conductivity for liquid refrigerants at atmospheric pressure or near saturation", International Journal of Refrigeration, 45, pp. 168-176, 2014. https://doi.org/10.1016/j.ijrefrig.2014.06.003

[14] Rostami, A., Ebadi, H., Arabloo, M., Meybodi, M. K., Bahadori, A. "Toward genetic programming (GP) approach for estimation of hydrocarbon / water interfacial tension", Journal of Molecular Liquids, 230, pp. 175-189, 2017. https://doi.org/10.1016/j.molliq.2016.11.099

[15] Najafi-Marghmaleki, A., Tatar, A., Barati-Harooni, A., Mohammadi, A. H. "A GEP based model for prediction of densities of ionic liquids", Journal of Molecular Liquids, 227, pp. 373-385, 2017. https://doi.org/10.1016/j.molliq.2016.11.072

[16] Zendehboudi, A., Angrisani, G., Li, X. "Parametric studies of silica gel and molecular sieve desiccant wheels: Experimental and modeling approaches", International Communications in Heat and Mass Transfer, 91, pp. 176-186, 2018. https://doi.org/10.1016/j.icheatmasstransfer.2017.12.002 
[17] Haghbakhsh, R., Raeissi, S. "A novel correlative approach for ionic liquid thermal conductivities", Journal of Molecular Liquids, 236, pp. 214-219, 2017. https://doi.org/10.1016/j.molliq.2017.03.117

[18] Rostamian, S. H., Biglari, M., Saedodin, S., Esfe, M. H., "An inspection of thermal conductivity of CuO-SWCNTs hybrid nanofluid versus temperature and concentration using experimental data, ANN modeling and new correlation", Journal of Molecular Liquids, 231, pp. 364-369, 2017. https://doi.org/10.1016/j.molliq.2017.02.015

[19] Jarrahian, A., Heidaryan, E. "A simple correlation to estimate natural gas thermal conductivity", Journal of Natural Gas Science and Engineering, 18, pp. 446-450, 2014. https://doi.org/10.1016/j.jngse.2014.04.005

[20] Eslamloueyan, R., Khademi, M. H. "Estimation of thermal conductivity of pure gases by using artificial neural networks", International Journal of Thermal Sciences, 48(6), pp. 1094-1101, 2009. https://doi.org/10.1016/j.ijthermalsci.2008.08.013

[21] Shams, R., Esmaili, S., Rashid, S., Suleymani, M. "An intelligent modeling approach for prediction of thermal conductivity of $\mathrm{CO}_{2}$ ", Journal of Natural Gas Science and Engineering, 27(1), pp. 138-150, 2015.

https://doi.org/10.1016/j.jngse.2015.08.050

[22] Di Nicola, G., Ciarrocchi, E., Pierantozzi, M., Stryjek, R. "A new equation for the thermal conductivity of organic compounds", Journal of Thermal Analysis and Calorimetry, 116(1), pp. 135-140, 2014. https://doi.org/10.1007/s10973-013-3422-7

[23] Bahadori, A., Vuthaluru, H. B. "Predictive tool for an accurate estimation of carbon dioxide transport properties", International Journal of Greenhouse Gas Control, 4(3), pp. 532-536, 2010. https://doi.org/10.1016/j.ijggc.2009.12.007

[24] Amooey, A. A. "A simple correlation to predict thermal conductivity of supercritical carbon dioxide", The Journal of Supercritical Fluids, 86, pp. 1-3, 2014. https://doi.org/10.1016/j.supflu.2013.11.016

[25] Ahmadi, M. A., Baghban, A. "Evolving simple-to-apply models for estimating thermal conductivity of supercritical $\mathrm{CO}_{2}$ ", International Journal of Ambient Energy, 38(3), pp. 300-307, 2017. https://doi.org/10.1080/01430750.2015.1086682

[26] Rostami, A., Arabloo, M., Ebadi, H. "Genetic programming (GP) approach for prediction of supercritical $\mathrm{CO}_{2}$ thermal conductivity", Chemical Engineering Research and Design, 122, pp. 164-175, 2017. https://doi.org/10.1016/j.cherd.2017.02.028
[27] Rostamian, H., Lotfollahi, M. N. "New Functionality for Energy Parameter of Redlich-Kwong Equation of State for Density Calculation of Pure Carbon Dioxide and Ethane in Liquid, Vapor and Supercritical Phases", Periodica Polytechnica Chemical Engineering, 60(2), pp. 93-97, 2016. https://doi.org/10.3311/PPch.8221

[28] Scott, A. C., Johns, A. I., Watson, J. T. R., Clifford, A. A. "Thermal conductivity of carbon dioxide in the temperature range $300-348 \mathrm{~K}$ and pressures up to $25 \mathrm{MPa}$ ", Journal of the Chemical Society, Faraday Transactions 1: Physical Chemistry in Condensed Phases, 79(3), pp. 733-740, 1983. https://doi.org/10.1039/F19837900733

[29] Johns, A. I., Rashid, S., Watson, J. T. R., Clifford, A. A. "Thermal conductivity of argon, nitrogen and carbon dioxide at elevated temperatures and pressures", Journal of the Chemical Society, Faraday Transactions 1: Physical Chemistry in Condensed Phases, 82(7), pp. 2235-2246, 1986. https://doi.org/10.1039/F19868202235

[30] Pátek, J., Klomfar, J., Čapla, L., Buryan, P. "Thermal Conductivity of Carbon Dioxide-Methane Mixtures at Temperatures Between 300 and $425 \mathrm{~K}$ and at Pressures up to $12 \mathrm{MPa}$ ", International Journal of Thermophysics, 26(3), pp. 577-592, 2005. https://doi.org/10.1007/s10765-005-5566-6

[31] Leneindre, B., Tufeu, R., Bury, P., Sengers, J. V. "Thermal Conductivity of Carbon Dioxide and Steam in the Supercritical Region", Berichte der Bunsengesellschaft für physikalische Chemie, 77(4), pp. 262-275, 1973. https://doi.org/10.1002/bbpc.19730770410

[32] Vesovic, V., Wakeham, W. A., Olchowy, G. A., Sengers, J. V., Watson, J. T. R., Millat, J. "The Transport Properties of Carbon Dioxide", Journal of Physical and Chemical Reference Data, 19(3), pp. 763-808, 1990. https://doi.org/10.1063/1.555875

[33] NIST Chemistry WebBook "Thermophysical Properties of Fluid Systems", [online] Available at: https://webbook.nist.gov/chemistry/fluid/ [Accessed: 20 February 2017] 